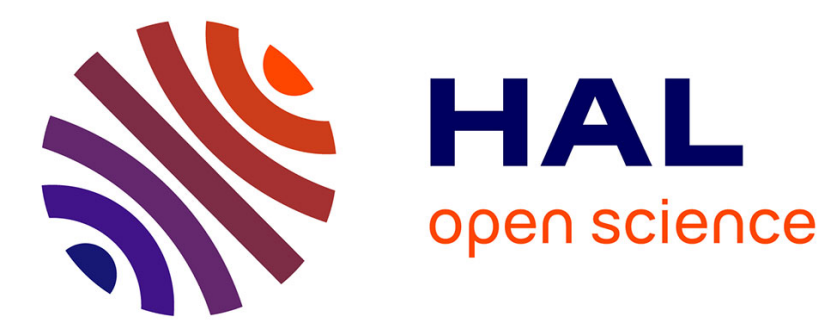

\title{
Benchmarking ionizing space environment models
}

S. Bourdarie, C. Inguimbert, J.-R. Vaillé, P. Calvel, A. Sicard-Piet, D.

Falguere, E. Lorfèvre, R. Ecoffet, C. Poivey

\section{To cite this version:}

S. Bourdarie, C. Inguimbert, J.-R. Vaillé, P. Calvel, A. Sicard-Piet, et al.. Benchmarking ionizing space environment models. RADECS 2016, Sep 2016, BREME, Germany. hal-01442246

\section{HAL Id: hal-01442246 \\ https://hal.science/hal-01442246}

Submitted on 20 Jan 2017

HAL is a multi-disciplinary open access archive for the deposit and dissemination of scientific research documents, whether they are published or not. The documents may come from teaching and research institutions in France or abroad, or from public or private research centers.
L'archive ouverte pluridisciplinaire $\mathbf{H A L}$, est destinée au dépôt et à la diffusion de documents scientifiques de niveau recherche, publiés ou non, émanant des établissements d'enseignement et de recherche français ou étrangers, des laboratoires publics ou privés. 


\title{
Benchmarking ionizing space environment models
}

\author{
S. Bourdarie, C. Inguimbert, J.-R. Vaillé, P. Calvel, A. Sicard-Piet, D. Falguere, E. Lorfèvre, R. Ecoffet, C. Poivey
}

Abstract: In flight feedback data are collected such as displacement damage doses, ionizing doses on board various space vehicles and are compared to predictions performed with (1) proton measurements performed with spectrometers data on board the same spacecraft if any and (2) protons spectrum predicted by the legacy AP8min model and the AP9 mean model.

\section{INTRODUCTION}

Because of their harmful effects on human bodies and spacecraft electronics, the Earth's radiation belts have been intensively studied since their discovery in 1958. Spacecraft engineers need a reliable and statistical description of the belts to design space missions. The current standard models, AE8 [1] and AP8 [2], were developed by NASA at the end of the 1970s and beginning of the 1980s. Different studies have put forward their shortcomings ([3] and [4]): inadequate resolution at low altitude, no variability on timescales less than a solar cycle, etc. To overcome these limitations a recent effort in the US has allowed to release the AE9 and AP9 specification models [4].

To better validate and control uncertainties on space environment specification models, a new tool has been developed in order to perform quick and accurate Benchmark of Ionizing Space Environment models (BISE).The main goal is to collect in flight measurements which are independent of specification model construction in order to ensure a fully independent validation. Accordingly, total ionizing dose (TID), displacement damage dose (DDD) and cumulative SEU EDAC counters are favored. Then, to evaluate the measured degradation it is of prime importance to collect details of the spacecraft, payload, electronic board and chip shielding, the ground calibrations of dosimeters, and diodes, or the cross-section of interaction to trigger a SEE in a memory.

In Section I, the BISE tool allows flying any spacecraft into existing space environment specification model and to deduce measured effects is described. In Section II flight data are presented and compared to model

This work was supported by grant $n^{\circ}$ R-S12/MT-0003-107 which is part of CNES R\&T program.

S. Bourdarie, C. Inguimbert, A. Sicard-Piet, D. Falguere are with ONERA The French aerospace lab/Département Environnement Spatial, 31400 Toulouse France (telephone; +33-562-2756, fax : +33-562-2569, e-mail: Sebastien.Bourdarie@onera.fr).

J.R. Vaillé is with the Université Montpellier 2-IES, 34095 Montpellier cedex 5, France, and also with the Université de Nimes, 30021 Nimes, France

P. Calvel, is with Thales Alenia Space, 26 Avenue Jean François Champollion, 31100 Toulouse, France

E. Lorfèvre and R. Ecoffet are with CNES, 18 av. E. Belin 31401 Toulouse, France

C. Poivey is with ESA-ESTEC, Keplerlaan 1 P.O. Box 299, 2200 AG Noordwijk ZH, The Netherlands predictions and in Section III uncertainties in models such as AP8 and AP9 are discussed.

\section{BISE TOOL}

The Benchmark of Ionizing Space Environment models tool (BISE) is written in IDL language and is set to provide all functionalities to build up the data base associated with in flight effect measurements, to plot support data, (i.e. shielding description around the parts under study, response function of the parts to the environment ..) and to compute the effects (TID, DDD ...) predicted from specification models and plot a comparison between model predictions and in flight observations (Fig. 1).

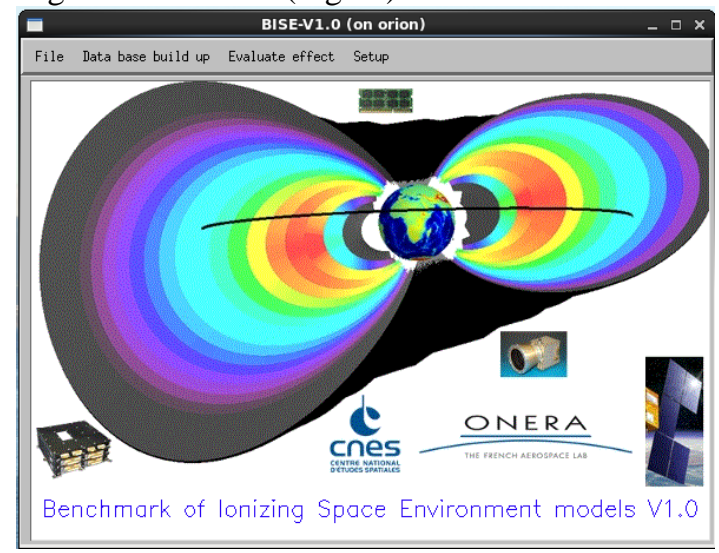

Fig. 1: Main window of the BISE tool

First of all, it is necessary to propagate the orbit of the spacecraft of interest (along which an effect under study could be further undertaken). To do so, the "two line element” orbit determination sets are retrieved from NORAD [5] and the spacecraft orbit is propagated with a 20 seconds time step for the mission duration based on the Simplified General Perturbation 4 [6] software (SGP4) using the BISE tool.

Second, trapped electron and proton specification environment models are implemented in the BISE software so that it is convenient to fly any spacecraft in the model of interest. The interface allows selecting a spacecraft registered in the database, a time period, a specification model and corresponding available versions and options and then retrieving the trapped environment along the orbit with a 20 seconds time step (Fig. 2). Note that when new specification model version comes up (as it is quite often the case with AE9/AP9) it is straightforward to include it in the tool and fly in. The trapped particle fluences from beginning of mission to each time when an effect measurement is available can be evaluated to predict any cumulative effect (TID, DDD). 


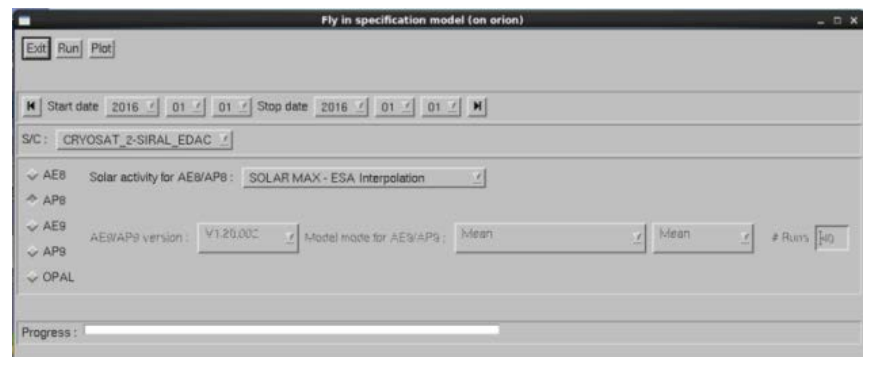

Fig. 2: Interface to fly a spacecraft in a user selected trapped particle specification model using the BISE software.

The BISE tool allows plotting support data as well, like the details being available to describe the 3D shielding around the electronic chip under study from a FASTRAD sectoring analysis (plot available under a fish eye view, back and front side or shielding thickness distribution) [7]. Three typical details of 3D spacecraft description are found, "no spacecraft", "6 faces" or "full". The response function of the chip to the environment can also be plotted, like the damage factor versus incident energy or ionizing dose factor versus incident energy ... Impact of different description of the 3D shielding can be analyzed and compared in an easy way.

Finally the tool evaluates cumulative effects measurements available in the database for all environment models that have been computed along the orbit of interest (see [8] for example for more details):

$\operatorname{Effect}(T)=\int_{0}^{T} \int_{E=1 \mathrm{MeV}}^{E=2 G e V} \frac{d \Phi}{d E}(E, t) \cdot R F(E) \cdot d E \cdot d t$

where $R F(E)$ is the response function, $\frac{d \Phi}{d E}$ the omnidirectional flux, and $\mathrm{E}$ the incident particle energy.

\section{IN FLIGHT DATA AND COMPARISON TO MODEL PREDICTIONS}

We concentrate here, on proton specification model validation. The in flight data available in the current study are organized according to increasing altitude.

\section{A. Total Displacement Damage Dose (DDD) at $660 \mathrm{~km}$ altitude}

SAC-D is an Argentinean spacecraft from CONAE flying on a Low Earth Orbit (circular orbit: $660 \mathrm{~km}$, inclination: $98^{\circ}, 14.12$ revolutions/day). It was launched on June 10, 2011. One of the payloads is the ICARE-NG instrument which was built in the frame of the CARMEN-1 ("CARactérisation et Modélisation de l'ENvironnement") suite (composed of ICARE-NG and SODAD instruments which have been funded by CNES). The ICARE-NG instrument on-board SAC-D began its operation in August 30, 2011 and stopped in June $7^{\text {th }} 2015$.

DDD is evaluated using the degradation of a Light Emitting Diode (LED) embedded in an OSL sensor which is part of the ICARE-NG instrument. The LED was fully calibrated before launch, in term of sensitivity to temperature and current through the LED versus DDD. All details about the instrument and data analysis can be found in [9]-[13]. The time resolution for the DDD is 6 hours and data from August 30, 2011 to November 6, 2014 are considered. Careful attention was taken to correct the temperature on the current through the LED (the temperature of the ICARE-NG is part of the housekeeping data of the instrument, see [13] for more details). Also, the conversion from LED current to DDD is done according to ground calibration [14].

To calculate an accurate DDD of the LED part of the OSL sensor, the 3D shielding around the OSL must be well known. The statistical distribution of shielding thicknesses seen by the OSL sensor on board SAC-D was calculated by a sector analysis carried out by the TRAD company using the FasTRAD software [7] (Fig. 3). Then, the response function $\mathrm{RF}(\mathrm{E})$ of the OSL sensor (Fig. 4) is calculated according to [8] as a function of proton incident energy, $\mathrm{E}(\mathrm{MeV})$, ), assuming $\frac{d \Phi}{d E}=1\left(\mathrm{MeV}^{-1} \mathrm{~cm}^{-2} \mathrm{~s}^{-1}\right)$.

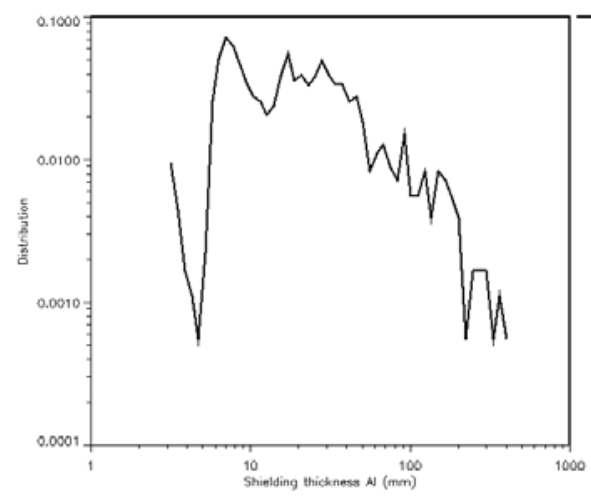

Fig. 3: Distribution of $\mathrm{Al}$ equivalent shielding thicknesses (in $\mathrm{mm}$ ) as viewed by the OSL sensor on board SAC-D spacecraft.

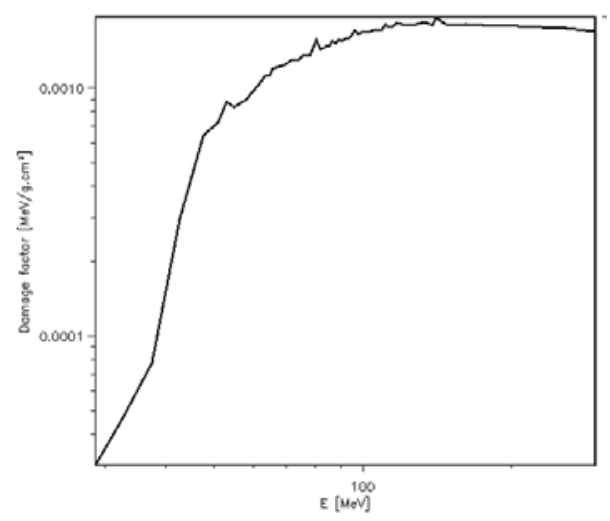

Fig. 4: Response function of damage factor of the OSL sensor considering isotropic proton incidence versus proton energy.

The ICARE-NG instrument is also composed of a radiation monitor. Two telescopes (A and $\mathrm{C}$ ) and a single detector (B) allow for measurement of electrons and protons in the energy range $250 \mathrm{keV}-3.2 \mathrm{MeV}$ and $12.8-190 \mathrm{MeV}$, respectively [15]. The time resolution is 16s. The integral channels, being omnidirectional, are used to retrieve the trapped proton environment at SAC-D altitude along the mission.

A comparison of cumulated OSL sensor DDD predicted from ICARE-NG spectrometers, AP8 min and AP9 V1.20.002 is shown in Fig. 5. The spectra from each model 
were imputed into Eq. 1 using the same shielding and response function. It turns out that the OSL DDD measures and those predicted from the ICARE-NG spectrometer measurements are within 10.7\%. AP8 min [1] and OPAL [16] specification models underestimate the OSL DDD by respectively, $10.7 \%$ and $8.6 \%$ while AP9 V1.20.002 Mean [4] overestimates the OSL DDD by $42.2 \%$.

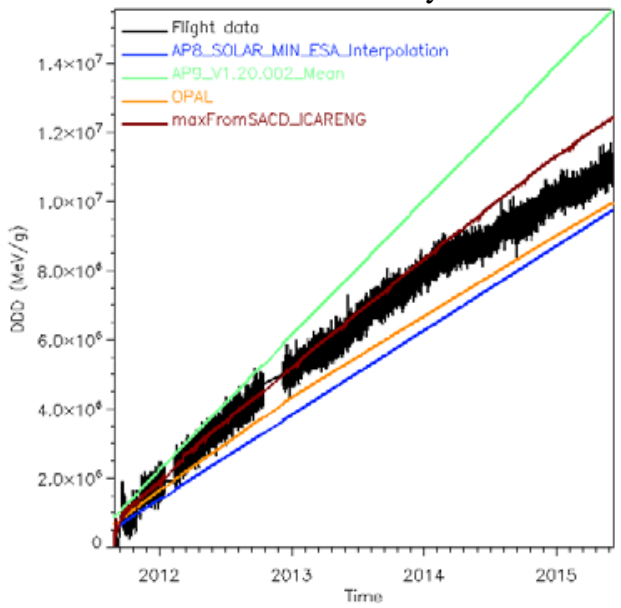

Fig. 5: Comparison of the measurements of the OSL DDD with those derived from the proton measurement with the ICARE-NG spectrometers, AP8 min, AP9 V1.20.002 Mean and OPAL along a $660 \mathrm{~km}$ altitude, $98^{\circ}$ inclination orbit.

\section{B. Total Displacement Damage Dose (DDD) at $1336 \mathrm{~km}$ altitude}

In [8] in-flight displacement damage on the OSL sensor was compared with prediction performed with space environment measured on board JASON-2 spacecraft as well as with prediction performed with AP8min and AP9V1.05 specification models.

In the current study an update is provided, where more recent in-flight data have been added and AP9V1.20.002 has been used (Fig. 6). Note that the energy integration in Eq. 1 has been improved since [8] such as an integration using a five-point Newton-Cotes integration formula was preferred to the integration by the method of the trapezoids.

The updates results are very consistent with conclusions in [8]:

- AP8min underestimates the DDD by $16.2 \%$

- AP9 mean V1.20.002 overestimates DDD by $113 . \%$

- $\quad$ Predictions from ICARE-NG spectrometers are within $4.8 \%$ to DDD flight data.

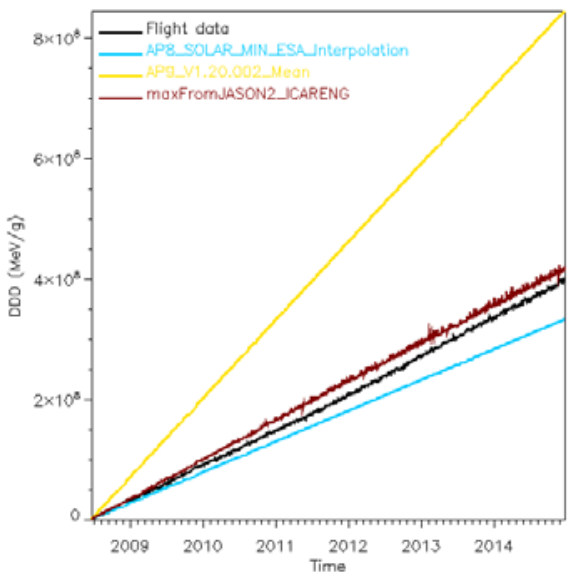

Fig. 6: Comparison of the measurements of the OSL DDD with those derived from the proton measurement with the ICARE-NG spectrometers and AP8 min, AP9 V1.20.002 Mean along a $1336 \mathrm{~km}$ altitude, 63 inclination orbit.

\section{Total Ionising Dose (TID) at $8070 \mathrm{~km}$ altitude}

O3B is a satellite constellation built by Thales Alenia Space and operated by O3B Networks Ltd. The orbit is circular at $8070 \mathrm{~km}$ altitude, $0^{\circ}$ inclination. The first four satellites were launched on 25 June 2013, and eight more in 2014. Inside the payload interface unit (PLIU) of each spacecraft, a RadFET manufactured by Tyndall National Institute and provided by ESA is implemented [17].

Two calibration campaigns were conducted, one at ESA and one at TRAD using $\mathrm{Co}^{60}$ radiation source, respecting the exact implementation of the RadFET into the O3B/PLIU. So far irradiation runs were performed at room temperature, i.e. $25^{\circ} \mathrm{C}$, to provide threshold voltage shift of the RadFET versus dose levels received.

To calculate an accurate TID of the RadFET, the 3D shielding around the chip must be well known. The statistical distribution of shielding thicknesses seen by the RadFET on board O3B was calculated by a sector analysis carried out by Thales Alenia Space using the FasTRAD software [7] (Fig. 7). Then, the response function RF(E) of the RadFET (Fig. 8) is calculated from a MCNPx V2.7.0 Monte-Carlo run .

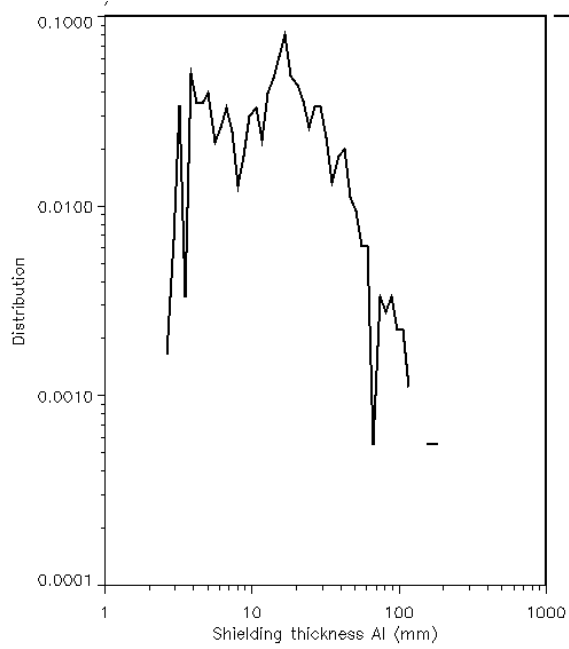

Fig. 7: Distribution of $\mathrm{Al}$ equivalent shielding thicknesses (in $\mathrm{mm}$ ) as viewed by the RadFET on board O3B spacecraft. 


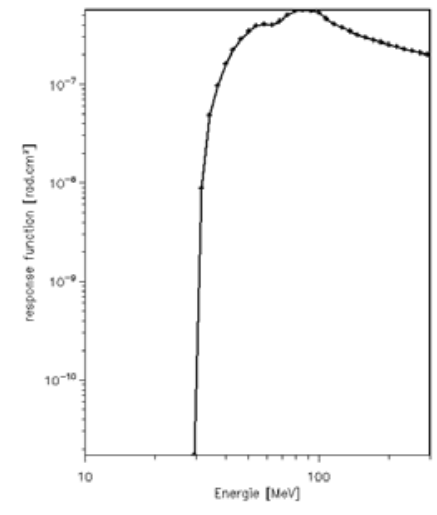

Fig. 8: Response function of ionizing dose factor of the RadFET considering isotropic proton incidence versus proton energy.

A comparison of TID predicted from AP8 min and AP9 V1.20.002 is shown in Fig. 9. The spectra from each model were imputed into Eq. 1 using the same shielding and response function. The results indicate that AP8 min and AP9 V1.20.002 Mean overestimates the TID by $161 \%$ and $1239 \%$ respectively.

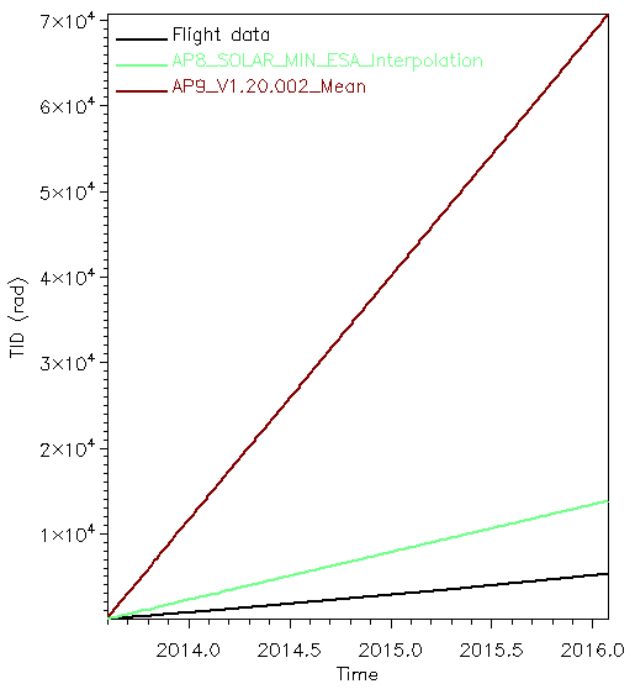

Fig. 9: Comparison of the measurements of the TID with those derived from AP8 min and AP9 V1.20.002 Mean along a $8070 \mathrm{~km}$ altitude, $0^{\circ}$ inclination orbit.

\section{CONCLUSIONS}

In-flight data showing cumulated effects such as DDD and TID have been used to investigate uncertainties in trapped proton specification models. Because careful attention was paid to incorporate the full 3D spacecraft geometry in the calculations as well as appropriate ground calibrations of the OSL/LED and the ESA-RaDFET, all errors in the process are under control.

In all cases, AP8 min is found to provide closer predictions to observations than AP9 V1.20.005 Mean. While in the 660-1336 km altitude range, AP8 underestimates proton fluxes with energy greater than $30 \mathrm{MeV}$ by $10-20 \%$ AP9 V1.20/005 Mean overestimates the observations by $40-$ $110 \%$. At the outer edge of the energetic proton belt, in the $8000 \mathrm{~km}$ altitude range, both AP8 min and AP9 1.20 .005 Mean overestimate observation respectively by $160 \%$ and $1240 \%$.
In the final paper, calculations will be performed with the latest AP9 model being available, thought version 1.30 has been released recently. Also, in the $700-1300 \mathrm{~km}$ altitude range more in-flight data will be compared to prediction. They are currently being processed.

\section{REFERENCES}

[1] D.M. Sawyer and J.I. Vette, "AP8 trapped proton model environment for solar maximum and minimum", NSSDC/WDC-A-R\&S 76-06, Natl. Space Sci. Data Cent., Greenbelt, MD, 1976.

[2] E. J. Daly, J. Lemaire, D. Heynderickx and D.J. Rodgers, "Problems with Models of the Radiation Belts", IEEE Trans. Nucl. Sci., vol. 43, no. 2, pp. 403-415, 1996.

[3] D.J. Rodgers, "Empirical Radiation Belt Models", AGU Geophysical Monograph 1997, 1997.

[4] G.P. Ginet; , T. P. O’Brien, S. L. Huston, W. R. Johnston, T. B. Guild, R. Friedel, C. D. Lindstrom, C. J. Roth, P. Whelan, R. A. Quinn, D. Madden, S. Morley and Y.-J. Su, "AE9, AP9 and SPM: new models for specifying the trapped energetic particle and space plasma environment”, Space science reviews, vol. 179, no. 1-4, pp. 579-615, 2013.

[5] Celestrak website: [Online]. Available: http://www.celestrak.com/NORAD/elements/

[6] Celestrak website [Online]. Available: http://celestrak.com/NORAD/documentation/spacetrk.pdf

[7] FASTRAD website: [Online]. Available: http://www.fastrad.net/

[8] S. Bourdarie Falguere, D.; Inguimbert, C.; Deneau, C.; Vaillé, J.-R.; Lorfèvre, E.; Ecoffet, R., "Correlation of in-flight displacement damage on the OSL sensor with space environment on-board Jason-2 spacecraft," in IEEE Transactions on Nuclear Science, vol. 61, no. 4, pp. 1643-1647, Aug. 2014., doi: 10.1109/TNS.2014.2315832.

[9] L. Dusseau, D. Plattard, J.-R. Vaillé, G. Polge, G. Ranchoux, F. Saigné, J. Fesquet, R. Ecoffet, and J. Gasiot, "An integrated sensor using optically stimulated luminescence for in flight dosimetry", IEEE Trans. Nucl. Sci., vol. 47, no. 6, pp. 2412-2416, 2000.

[10] D. Plattard, G. Ranchoux, L. Dusseau, G. Polge, J.-R. Vaille, J. Gasiot, J. Fesquet, R. Ecoffet, and N. Iborra-Brassart, "Characterization of an integrated sensor using optically stimulate luminescence for in-flight dosimetry", IEEE Trans. Nucl. Sci., vol. 49, no. 6, pp. 1322-1326, 2002.

[11] J.-R. Vaillé, F. Ravotti, P. Garcia, M. Glaser, S. Matias, K. Idri, J. Boch, E. Lorfèvre, P. J. McNulty, F. Saigné, and L. Dusseau, "Online dosimetry based on optically stimulated luminescence materials", IEEE Trans. Nucl. Sci., vol. 52, no. 6, pp. 2578-2582, 2005.

[12] P. Garcia, J.-R. Vaillé, D. Benoit, F. Ravotti, L. Artola, B. Sagnes, E. Lorfèvre, F. Bezerra, and L. Dusseau, "Study of the thermal behavior of the OSL integrated sensor response”, IEEE Trans. Nucl. Sci., vol. 54, no. 6, pp. 2272-2275, 2007.

[13] C. Deneau, J.-R. Vaillé, L. Dusseau, J. Mekki, P. Garcia, F. Bezerra, E. Lorfèvre, and R. Ecoffet, "First In-Flight Data Analysis of Displacement Damage on the OSL Sensor On-Board CARMEN-2", IEEE Trans. Nucl. Sci., vol. 58, no.3, pp. 939-944, 2011.

[14] P. Garcia, J.-R. Vaillé, D. Benoit, H. Chabane, G. Berger, K. Idri, J. Boch, B. Sagnes, F. Saigné, E. Lorfèvre, F. Bezerra, and L. Dusseau, "Simultaneous evaluation of TID and displacement damage dose using a single OSL sensor”, IEEE Trans. Nucl. Sci., vol. 53, no. 6, pp. 37133717, 2006.

[15] D. Boscher, Cayton, T.; Maget, V.; Bourdarie, S.; Lazaro, D.; Baldran, T.; Bourdoux, P.; Lorfevre, E.; Rolland, G.; Ecoffet, R., "In-Flight Measurements of Radiation Environment on Board the Argentinean Satellite SAC-D," in IEEE Transactions on Nuclear Science, vol. 61, no. 6, pp. 3395-3400, Dec. 2014. doi: 10.1109/TNS.2014.2365212.

[16] D. Boscher, A. Sicard-Piet, D. Lazaro, T. Cayton and G. Rolland, "A New Proton Model for Low Altitude High Energy Specification," in IEEE Transactions on Nuclear Science, vol. 61, no. 6, pp. 3401-3407, Dec. 2014. doi: 10.1109/TNS.2014.2365214.

[17] A. Jaksic, "New RADFETs for space applications," in ESA-ESTEC, 2009 